\title{
Analytical Thermal Rating Method for Cables Installed in J-Tubes
}

\author{
R. D. Chippendale, J. A Pilgrim, Member, IEEE, K. F. Goddard, P. Cangy
}

\begin{abstract}
One possible thermal pinch point along the route of a wind farm export circuit is a $J$ tube, commonly used to provide mechanical protection to cable sections between the sea floor and the offshore platform. Current ratings for such cable sections are not covered by the scope of IEC 60287, while the existing publications covering such systems have limitations. This paper presents an updated $2 D$ analytical method and a 3D extension for the rating of $\mathbf{J}$ tubes with short air section lengths. Continuous rating comparisons have been made against a 3D finite element model which shows a $4.5 \%$ variation in rating from the $2 D$ analytical model for air section lengths greater than $10 \mathrm{~m}$, rising to $13 \%$ for short air section lengths. With the addition of longitudinal heat transfer within the new 3D analytical approach this variation decreases by $2.5 \%$. Both methods proposed can be solved readily using conventional spreadsheet tools and are broadly compliant with the IEC 60287 methodology.
\end{abstract}

Index Terms - Power cable insulation, Power transmission, Wind energy integration, Wind farms, Modelling, offshore installations.

\section{INTRODUCTION}

I NCREASING numbers of off shore wind farms are now under construction or in operation in European waters. In order to ensure that the electricity generated is as competitive as possible with conventional sources, the costs of all system components are under scrutiny [1] [2]. The correct sizing of high voltage cables, both within turbine arrays and for export systems, is hence critical [3]. At present an internationally recognized standard (IEC 60287 [4] [5]) presents a collection of analytical methods to predict the thermal rating of numerous typical onshore cable installations. In recent years many studies have presented new or updated methods to predict the thermal ratings of non-standard installation [6] [7] as well as obtaining a more accurate rating by considering a more complete set of physical processes [8] [9] and better representing the thermal impact of the surrounding medium [10] [11]. At present there is no standard method for rating the section of cable in the protective J-tube between the sea floor and the offshore platform. Given the relatively complex three dimensional thermal environment in which these cable sections operate, they can often become the limiting factor on the overall circuit rating. In order to address this issue, this

R.D. Chippendale, J. A. Pilgrim, K. F. Goddard and P. Cangy are with the Tony Davies High Voltage Laboratory, University of Southampton, Southampton, UK, SO17 1BJ. (e-mail: rd.chippendale@soton.ac.uk).

All data supporting this study are openly available from the University of Southampton repository at http://dx.doi.org/10.5258/SOTON/xxxxx paper presents a three dimensional analytical rating calculation which can be used to rate these sections. Results obtained from the new method are contrasted with existing published methods which have been applied to such cable sections previously, along with the results of a full three dimensional finite element model. The proposed model is intended to be compatible with existing IEC 60287 calculation approaches and solved with standard software used for such purposes.

\section{J TUBE SySTEMS}

A typical J tube layout, as shown in Fig. 1, is comprised of three sections:

1. Tube water section, where the $\mathrm{J}$ tube annulus is filled with sea water.

2. Tube air section, above the sea level but below the hang off, where the annulus is air filled.

3. Above the hang off, the separate power core phases are exposed, (without armouring) and run in air to the substation.

The cable designs used in this study are based on a typical $1000 \mathrm{~mm}^{2} 132 \mathrm{kV} 3$ phase XLPE insulated SL type cable of the type commonly used for wind farm export systems. Full details of the cable geometry and properties, sufficient for the reproduction of key results, are given in the Appendix. Owing to the design of the hang off, it can be assumed that the $\mathrm{J}$ tube is effectively sealed at the top.

\section{EXISTING RATING METHODS}

Two principle published methods have been used to calculate the continuous seasonal ratings for $\mathrm{J}$ tube installations. Both methods consider only the central $\mathrm{J}$ tube air section, hence neglecting the longitudinal flow of heat to the $\mathrm{J}$ tube section below sea level or above the cable hang off.

\section{A. Empirical Method}

An empirically derived method for $\mathrm{J}$ tube thermal calculations was published by ERA in 1988 [12]. The cables around which the empirical method was derived had outer diameters between $75 \mathrm{~mm}$ and $130 \mathrm{~mm}$ and tube diameters between $160 \mathrm{~mm}$ and $400 \mathrm{~mm}$. The cable and $\mathrm{J}$ tube diameters considered here are in excess of $200 \mathrm{~mm}$ and $530 \mathrm{~mm}$, respectively. Since these values are greater than the range of the original experimental data, the ratings predicted by this method must be used with caution. The method is intended for use with $\mathrm{J}$ tubes which are sealed at the top, meaning that no significant exchange of air takes place between the tube annulus and ambient. The continuous rating is calculated by 
recognizing that under steady state conditions, the permissible heat flux across each radial component must be the same.

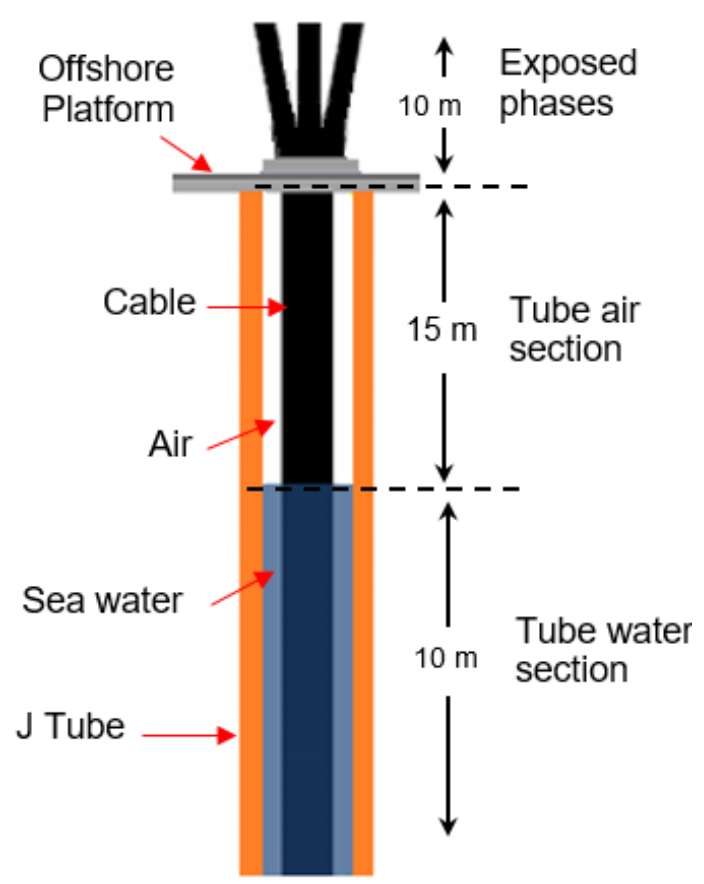

Fig. 1. General arrangement of a typical J tube

Inherent within the balanced permissible heat flux statement is the assumption that minimal heat is produced within the armour and sheath. Published studies have shown that there is a considerable sheath loss within SL type cables [13], and so this assumption of only conductor loss being present is a further limitation of this rating approach. The total permissible heat flux through each region is related to the temperature drop across each region using simultaneous equations, with the conductor region presented in (1), the insulation in (2) and the $\mathrm{J}$ tube air section in (3).

$$
\begin{gathered}
\mathrm{W}_{\mathrm{c}}=\frac{\Delta \theta_{\mathrm{c}}}{\mathrm{T}_{\mathrm{i}}} \\
\mathrm{W}_{\mathrm{i}}=20.3 \mathrm{D}_{\mathrm{i}}^{0.315} \mathrm{D}_{\mathrm{e}}^{0.73} \Delta \theta_{\mathrm{p}}^{1.05} \\
\mathrm{~W}_{\mathrm{e}}=\pi \mathrm{D}_{\mathrm{o}} \mathrm{h}_{\mathrm{era}} \Delta \theta_{\mathrm{s}}^{1.09}-\mathrm{q}_{\text {solar }} \mathrm{D}_{\mathrm{o}} \alpha
\end{gathered}
$$

Where, $D_{e}, D_{i}$ and $D_{o}$ are the diameter of the cable surface $(\mathrm{m})$, inside wall of the $\mathrm{J}$ tube $(\mathrm{m})$ and outside wall of the $\mathrm{J}$ tube surface $(\mathrm{m})$. The temperature difference between the conductor and cable surface is $\Delta \theta_{c}(\mathrm{~K})$, between the cable surface and the tube $\Delta \theta_{p}(\mathrm{~K})$ and between the tube and the ambient $\Delta \theta_{s}(\mathrm{~K})$. The total thermal resistivity of the cable is given by $T_{i}\left(\mathrm{KW}^{-1}\right)$ and is calculated according to IEC 60287-2 [5]. The heat transfer coefficient from the cable surface is $h_{\text {era }}$ $\left(\mathrm{Wm}^{-2} \mathrm{~K}^{-1}\right)$ and the solar heat flux $q_{\text {solar }}\left(\mathrm{Wm}^{-2}\right)$ and $\alpha$ is the absorptivity.

To complete the above set of equations, the sum of the temperature decrease in each section is defined with respect to the maximum allowed conductor temperature $\left(\theta_{\text {max }}\right)$ minus the ambient temperature $\left(\Delta \theta_{a m b}\right)$, which is expressed as:

$$
\left(\theta_{\max }-\theta_{a m b}\right)=\Delta \theta_{c}+\Delta \theta_{p}+\Delta \theta_{s}
$$

By varying the temperature difference within each region it is possible to obtain the same permissible heat flux through each region. The permissible heat flux solution is then used in conjunction with IEC 60287-1 to calculate the continuous rating required to achieve this permissible heat flux.

\section{B. Analytical Method}

An analytical method for the rating of cables in risers similar to $\mathrm{J}$ tubes was proposed by R.A. Hartlein and W. Z Black in 1983 [14]. It is based around a thermal network model and is more general in its applicability than [12], considering tubes which are both open and sealed at the top. The ladder network for the cable is akin to the network layout within IEC 60287-2, with the temperature difference $(\Delta \theta)$ between two radial positions being given as

$$
\Delta \theta=q^{\prime} T
$$

Where $q^{\prime}\left(\mathrm{Wm}^{-2}\right)$ is the heat flux passing through the region which has a thermal resistance, $T\left(\mathrm{KW}^{-1}\right)$. The thermal resistance for an annulus is given by

$$
T=\frac{\rho_{k}}{2 \pi} \ln \left[\frac{r_{o}}{r_{i}}\right]
$$

Where $\rho_{k}$ is the thermal resistivity $\left(\mathrm{KmW}^{-1}\right)$ of material ' $k$ ' and $r_{i}$ and $r_{o}$ are the inner and outer radius of the annulus region. The design of a thermal network for a three core cable is complicated by the non-radially symmetric layup. The thermal resistance used in [14] for the three core cable $\left(\mathrm{T}_{3}\right.$ cables) is defined as

$$
T_{3 \text { cables }}=\frac{7}{18} T_{1 \text { cable }}
$$

It is worth noting that this definition does not match the conventional IEC 60287 approach for a three core cable. However both methods assume that the three core cable can be represented as an equivalent single core cable. Through this modified thermal resistance the outer radius of the cable defined by [14] is

$$
r_{3 \text { cable }}=2.15 r_{1 \text { cable }}
$$

To represent the heat flux between the cable surface and the J-tube, a thermal energy balance is needed between the total thermal losses within the cable $\left(q_{\text {total }}\right)$ with the convective $\left(q_{\text {conv int }}\right)$ and radiation $\left(q_{\text {rad int }}\right)$ heat transfer from the cable surface. This energy balance is expressed as

$$
q_{\text {total }} L=q_{\text {conv int }}+q_{\text {rad int }}
$$

The convective heat transfer from the cable surface ( $\left.\theta_{\text {cable }}\right)$ to the $\mathrm{J}$ tube inner surface $\left(\theta_{\mathrm{j} \text { inner }}\right.$ ) is given by

$$
q_{\text {conv int }}=\left(\pi D_{i} L\right) h_{h b}\left\{\theta_{\text {cable }}-\theta_{\mathrm{j} \text { inner }}\right\}
$$

Where $D_{i}$ is the inside diameter of the $J$ tube $(m)$. The radiation heat transfer between the same two surfaces is

$$
q_{\text {rad int }}=\frac{\pi D_{i} \sigma\left\{\theta_{\text {cable }}^{4}-\theta_{j \text { inner }}^{4}\right\}}{1+\frac{\rho_{\text {cable }}}{\varepsilon_{\text {cable }}}+\frac{A_{\text {cable }} \rho_{j}}{A_{j \text { inner }} \varepsilon_{j}}}
$$

Where $\rho$ and $\varepsilon$ are the reflectivity and emissivity of the cable (cable) or the $J$ tube $(j)$ surface. Finally $A_{\text {cable }} \& A_{j}$ inner are the surface area of the cable $\left(\mathrm{m}^{2}\right)$ and the inside surface of the $\mathrm{J}$ tube $\left(\mathrm{m}^{2}\right)$. The heat transfer coefficient on the cable surface $\left(h_{h b}\right)$, has been empirically determined to be [14] 


$$
h_{h b}=\frac{c K_{\text {air }}}{L}\left[\frac{g \beta\left\{\theta_{\text {cable }}-\theta_{j \text { inner }}\right\} L^{3} P r}{v^{2}}\right]^{n}
$$

The term within the brackets which is raised to the power $n$, is the Nusselt number and its form is dependent on geometric factors, whether the tube is open or closed, and finally the thermal gradient across the air gap. The values of $c$ and $n$ have been calculated from experimental studies as a function of Rayleigh number [14]. A more detailed review of potential Nusselt numbers for this situation is presented in [15].

The temperature on the inside surface of the $\mathrm{J}$ tube $\left(\theta_{j \text { inner }}\right)$ can then be calculated from (9) using the Newton-Raphson method. A detailed example of this is included within [14]. Using the thermal network method given in [5] the outside temperature of the J-tube $\left(\theta_{j \text { outer }}\right)$ can be calculated from $\theta_{j \text { inner }}$. The temperature on the outside of J-tube is then used to solve the heat flux balance from the $\mathrm{J}$ tube to ambient environment, with the following equality

$$
q_{\text {total }} L+0.5 \pi D_{o} L \alpha q_{\text {solar }}=q_{\text {conv ext }}+q_{\text {rad ext }}
$$

Where the convective $\left(q_{\text {conv ext }}\right)$ and radiation $\left(q_{\text {rad ext }}\right)$ losses from the tube are expressed as

$$
q_{\text {conv ext }}=\left(\pi D_{O} L\right) h_{\text {ext }}\left\{\theta_{j \text { outer }}-\theta_{\text {surf }}\right\}
$$

And

$$
q_{\text {rad ext }}=\pi D_{O} L \varepsilon_{j} \sigma\left\{\theta_{j \text { outer }}^{4}-\theta_{\text {surf }}^{4}\right\}
$$

Where $h_{\text {ext }}$ is the heat transfer coefficient on the tube surface, which is given by $h_{h b}\left(\mathrm{Wm}^{-2} \mathrm{~K}^{-1}\right), \alpha$ is the thermal absorption of the $\mathrm{J}$ tube, $q_{\text {solar }}$ is the solar heat flux $\left(\mathrm{Wm}^{-2}\right)$ and $\mathrm{D}_{\mathrm{o}}$ is the outside diameter of the $\mathrm{J}$ tube $(\mathrm{m})$. It is assumed that the emissivity is the same on the inside and outside surface of the $\mathrm{J}$ tube.

The cable rating is then obtained by defining a maximum conductor temperature and an initial approximation for the circuit load required to achieve this conductor temperature. This initial approximation is then iteratively improved by comparing the predicted ambient temperature $\left(\theta_{\text {surf }}\right)$, with the actual ambient temperature $\left(\theta_{a m b}\right)$.

\section{Finite ElEMENT ANALySIS MODEL}

Prior to introducing the new analytical methods proposed by this paper, it is useful to consider in more detail the requirements of such a method. In order to demonstrate the thermal behavior of a typical $\mathrm{J}$ tube system, and to act as a comparator to the analytical results, a 3D Finite Element (FE) model has been developed to predict the thermal profile within a $\mathrm{J}$ tube. This model only represents directly the cable and $\mathrm{J}$ tube itself, with the interaction with ambient handled via boundary conditions. The steady state temperature $(\theta)$ profile within all solid domains due to conduction is solved using

$$
[\kappa \nabla \theta]+Q=0
$$

Here, $\kappa$ is the thermal conductivity of the domain $\left(\mathrm{Wm}^{-1} \mathrm{~K}^{-1}\right)$ and $Q$ is the volumetric heat source $\left(\mathrm{Wm}^{-3}\right)$. Within a cable the principle heat sources are the electrical losses within the conductor, dielectric, sheath and armour wires and these are defined within the model using the expressions given in IEC 60287-1 [4], using the cable parameters detailed in the Appendix. The induced thermal loss within the $\mathrm{J}$ tube itself is assumed to be negligible where it contains a balanced three phase SL type cable, given the relatively small induced losses in the cable armour itself [4].

Whilst the majority of the modeling domains are solid, there are two non-solid domains; the water and air between the cable and the J tube. Since it is computationally expensive to solve the 3D Navier stokes equations for non-isothermal fluid behavior it is important to determine if there are other appropriate techniques which can predict the heat transfer within these fluid regions. In regards to the water between the $\mathrm{J}$ tube and the cable, due to the relatively small thermal gradient available to drive the convective cell and because the thermal conductivity of water is relatively high, the natural convection can be deemed negligible and so the water can be thermally assumed to be a solid.

The same assumption cannot be made for the air within the $\mathrm{J}$ tube, due to the poor thermal conductivity of air. To avoid solving the Navier-stokes equations, the convective heat transfer can be modeled through an analytical natural convection method. A comprehensive review of the analytical heat transfer coefficient used in this paper is presented in the original derivation of the chosen Nusselt number in [16]. This approach considers that the convective heat transfer is proportional to the temperature difference between the cable $\left(\theta_{\text {cable }}\right)$ and the $\mathrm{J}$ tube surface $\left(\theta_{\text {Jinner }}\right)$, as defined by

$$
q_{\text {conv }}=h_{\text {conv }}\left(\theta_{\text {cable }}-\theta_{\text {Jinner }}\right)
$$

The constant of proportionality, $h_{\text {conv }}$ is the empirical heat transfer coefficient, which is calculated by [17]

$$
h_{\text {conv }}=\frac{N u \kappa_{\text {air }}}{\delta_{g}}
$$

Where $\kappa_{\text {air }}$ is the thermal conductivity of the air $\left(\mathrm{Wm}^{-1} \mathrm{~K}^{-1}\right)$ and $\delta_{g}$ is the distance between the cable surface and the $\mathrm{J}$ tube inner wall $(\mathrm{m})$. The empirically derived Nusselt number $(\mathrm{Nu})$ for an annulus is defined by [17]

$$
N u=0.188 R a^{0.322} \frac{L^{-0.238}}{\delta_{g}}{\frac{D_{i}}{D_{\text {cable }}}}^{0.442}
$$

Where $D_{\text {cable }}$ and $D_{i}$ are the diameter of the cable and the inside surface of the $J$ tube $(\mathrm{m})$. The Reynolds number $(\mathrm{Ra})$ is defined by

$$
R a=\frac{\operatorname{Pr} g \beta\left(\theta_{\text {Jinner }}-\theta_{\text {cable }}\right) \delta_{g}^{3}}{v^{2}}
$$

Where $\operatorname{Pr}$ is the Prandtl Number, which under typical ambient air temperature is assumed to be 0.71 . The gravitational constant $(g)$ is $9.8 \mathrm{~ms}^{-1}$, the coefficient of volumetric expansion of air $(\beta)$ is $0.003 \mathrm{~K}^{-1}$ and kinematic viscosity of air $(v)$ is $20 \mu \mathrm{m}^{2} \mathrm{~s}^{-1}$ [14].

To account for the convection from the cable surface to the internal $\mathrm{J}$ tube surface the integral of convective heat flux from the cable surface is re-distributed uniformly over the inner $\mathrm{J}$ tube surface. The surface to surface radiation between the cable and $\mathrm{J}$ tube is defined by the temperature difference between the cable surface $\left(\theta_{\text {cable }}\right)$ and the inner surface of the $\mathrm{J}$ tube $\left(\theta_{j \text { inner }}\right)$ as by

$$
q_{\text {rad }}=\varepsilon \sigma\left(\theta_{\text {cable }}^{4}-\theta_{j \text { inner }}^{4}\right)
$$

Where $\sigma$ is the Stefan-Boltzmann constant, $\varepsilon$ is the surface emissivity, which is taken to be 0.9 . Whilst the paint color and 
finish does affect this, such an emissivity is a reasonable assumption.

\section{A. External Boundary Conditions}

With the internal physical processes defined, the final aspects to define are the external boundary conditions. The $\mathrm{J}$ tube surface below sea level is assumed to be at a season independent constant temperature of $10{ }^{\circ} \mathrm{C}$. Such an assumption is reasonable due to the large volume of water and its small continual tidal movement.

The external surfaces above sea level are considered to be affected by natural convection and surface to ambient radiation. Both the natural convection to ambient and the surface to ambient radiation are implemented in the same manner as that for the cable surface, i.e. (17) and (21) respectively. The only difference on the external boundary condition is that the temperature difference is replaced by that of ambient $\left(\theta_{\text {amb }}\right)$ and the outer $\mathrm{J}$ tube surface $\left(\theta_{\mathrm{J} \text { outer }}\right)$. The external ambient temperature is assumed to be $30^{\circ} \mathrm{C}$.

All external surfaces above the sea level also have an incident solar heat flux. This heat flux is defined by $60287-2$ [5] as $1000 \mathrm{Wm}^{-2}$ for all seasons. The absorptivity of the $\mathrm{J}$ tube surface is assumed to be 0.4 [14]. This heat flux was halved based on the assumption that at any one time, the solar heat flux only affects half of the surface due to shadowing.

\section{FE RESULTS}

The conductor temperature profile predicted by the FE model at a continuous load of $828 \mathrm{~A}$ is presented in Fig. 2.

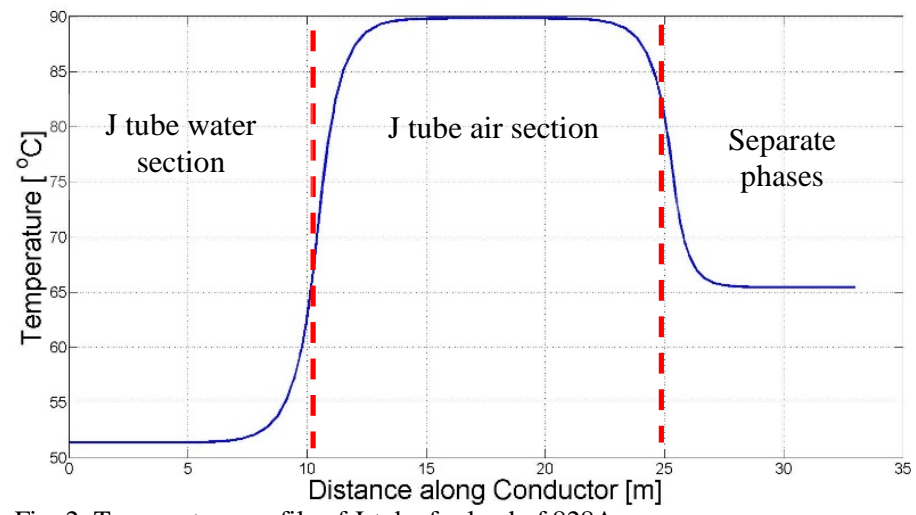

Fig. 2. Temperature profile of J-tube for load of 828A

The temperature profile presented in Fig. 2 shows three distinct regions, which correspond to the three $\mathrm{J}$ tube sections noted in Section II. The hottest temperature within the J tube is observed within the air section. Starting at $10 \mathrm{~m}$ below the sea level (length equal to $0 \mathrm{~m}$ in Fig. 2), the conductor temperature is approximately constant below the sea level due to assumption of a uniform water temperature within the tube. However as the tube air section approaches, the temperature begins to increase, due to longitudinal heat transfer from the hotter central region. The increase in temperature within the central region is caused by both an effective increase in thermal resistance between the cable surface and ambient, plus the addition of the solar heat flux. Within the tube air section, the temperature continues to increase up to a plateau. This temperature plateau is formed due to the diminishing longitudinal heat transfer from the hotter central $\mathrm{J}$ tube air section to the cooler neighboring sections. The conductor temperature decreases once the phases are separated, due to the reduction in thermal resistance caused by the removal of the amour layer and associated binders and fillers.

From these initial results it is apparent that the longitudinal heat transfer from the central region to the cooler sections, and the thermal resistance between the cable and the $\mathrm{J}$ tube surface, could play a significant impact on the conductor temperature profile and hence the thermal rating.

The results of the 3D model where the length of the tube is varied are shown in Fig. 3. The $1000 \mathrm{~mm}^{2}$ cable is loaded with a continuous 828 A. From Fig. 3 it is apparent that for lengths greater than approx. $7.5 \mathrm{~m}$ the conductor temperature plateau is formed. This is because as the length of the air section increases there comes a point where the distance is large enough such that there is no effective longitudinal heat transfer in the tube air section, thus a plateau forms. For tube air section lengths shorter than $7.5 \mathrm{~m}$ there is a decrease in peak conductor temperature for the same load. It should therefore be noted that it is only accurate to consider a 2D slice model if the $\mathrm{J}$ tube air section length is greater than $10 \mathrm{~m}$. For most installations, this would prove acceptable (due to the height of the offshore platform above mean sea level). The possible impact on the rating due to the longitudinal heat transfer is presented in Fig. 4 for various conductor sizes within the same design family. The percentage increase in rating uses the rating from the $15 \mathrm{~m}$ air section length as a reference.

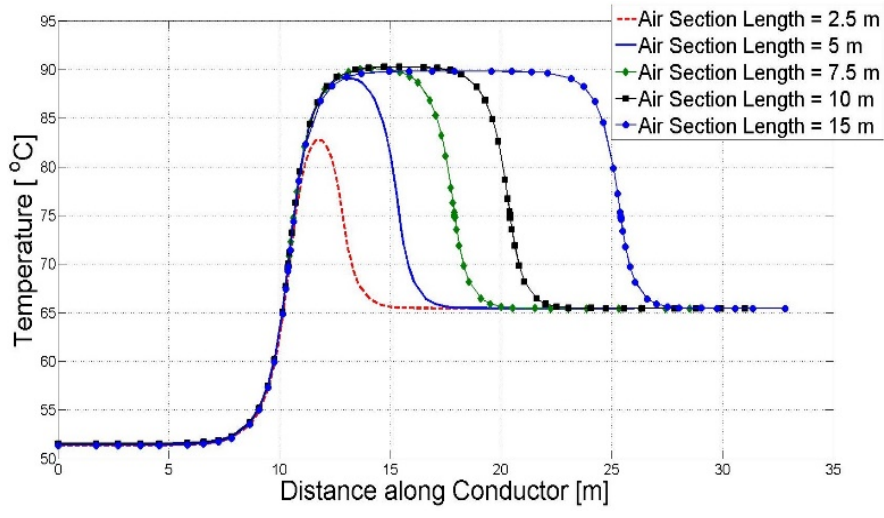

Fig. 3. Conductor temperature profile of varying the length of the air section

From Fig.4 it is apparent that as the conductor cross sectional area (XSA) increases from $630 \mathrm{~mm}^{2}$ to $1200 \mathrm{~mm}^{2}$ the rating increase associated with the longitudinal heat transfer rises by up to $11.5 \%$. Such an increase with XSA is expected due to the reduced thermal resistance of a larger conductor increasing the permissible heat flux into neighboring cooler regions. Despite this the air section length where an increase in rating is possible is independent of XSA at approximately $7.5 \mathrm{~m}$. 


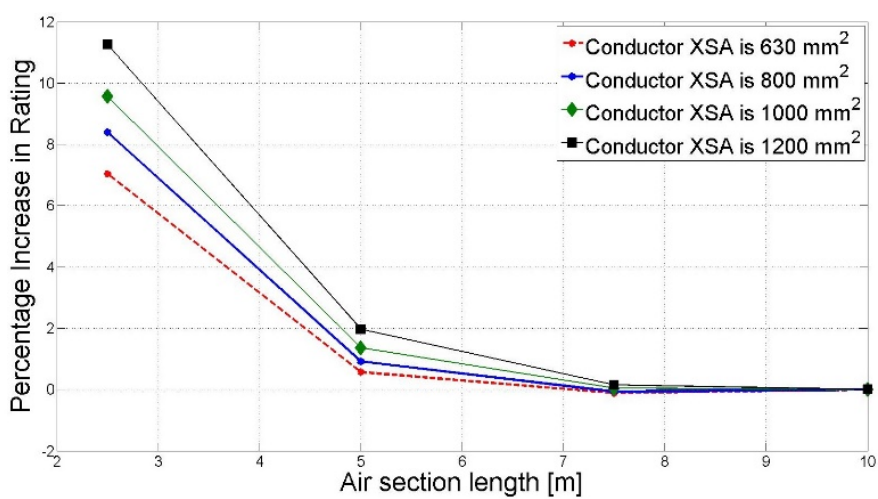

Fig 4. Percentage increase in continuous rating as a function of $\mathrm{J}$ tube air section length for various conductor sizes

\section{Proposed Analytical Method}

Having reviewed the existing methods, and considering the thermal profiles seem from the finite element model in Section IV, a new analytical method is proposed which is more in line with IEC 60287 approaches. Three component models are used, one for each of the three thermal sections, as outlined in fig.5. The thermal network for the central air section is outlined first, before describing the network for the neighboring sections.

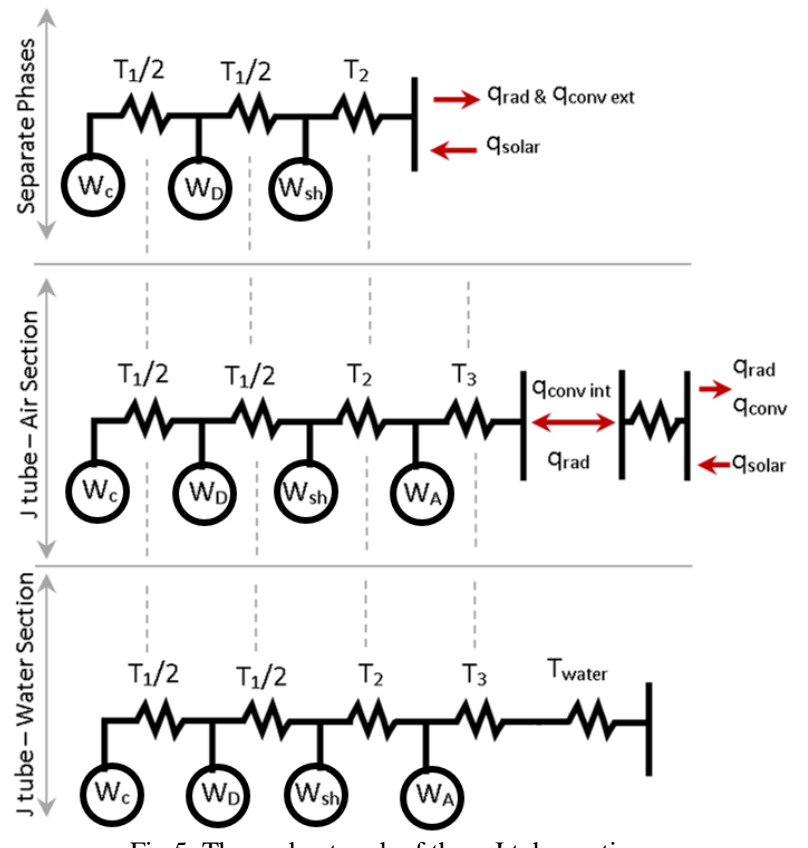

Fig 5. Thermal network of three $\mathrm{J}$ tube sections

\section{A. Cable Model}

The thermal network of the 3 core SL type cable is developed following the methods given in IEC 60287-2. Inherent within this approach is the same assumption that the three core cable can be represented by a single core cable. As such, expressions for $\mathrm{T}_{1}, \mathrm{~T}_{2}$ and $\mathrm{T}_{3}$ (as defined by IEC 602872 [5]) are used. Recent publications have considered updating the typical IEC thermal network to remove the single core assumption [18]. However as the current IEC method does present reasonable agreement for 3 core SL type cables when compared against $\mathrm{FE}$ results in this paper they shall be considered here. The thermal losses with the cable are also defined as per IEC 60287 [4]. The IEC armour loss has been chosen despite recent publications indicating [13] that this might be an over estimation of the thermal armour loss, as the aim is simply to demonstrate the functionality of the method.

\section{B. Heat Transfer in air between cable and J Tube}

The heat transfer between the cable and the inside surface of the $\mathrm{J}$ tube is dependent on the thermal convection and surface to surface radiation, thermal conduction through the air being neglected. The basis of this approach relies on the energy balance, as with the method proposed by Hartlein and Black [14]. Whilst the thermal convection is solved using the same analytical heat transfer method, the heat transfer coefficient is updated following the discussions presented in [17], where $h_{\text {conv }}$ is defined by (18), as used in the numerical model rather than $h_{h b}$. The surface to surface radiation is calculated using the same method proposed by Hartlein and Black [14] in (11).

\section{Heat Transfer through J Tube Air Section}

The temperature difference across the $\mathrm{J}$ tube is calculated in accordance with [5] by

$\theta_{j \text { outer }}=\theta_{j \text { inner }}-\left[I^{2} R_{a c} n\left(1+\lambda_{1}+\lambda_{2}\right)+W_{d} n\right] T_{\text {tube }}$

Where $T_{\text {tube }}$ is the thermal resistance of the $\mathrm{J}$ tube annulus, which can be calculated by (6). For a metallic J tube, this temperature difference will be small, and so could be neglected. This term is therefore only included for completeness, as there could be situations where the $\mathrm{J}$ tube is constructed from a less thermally conductive material and so would have a greater temperature difference.

\section{Heat Transfer from J Tube to Ambient}

The heat transfer from the $\mathrm{J}$ tube external surface is expressed using convection, radiation and the solar heat flux. The permissible heat flux and resultant $\mathrm{J}$ tube surface temperature is solved through a comparable permissible heat flux balance as given by (9).

However the external convection should be modified to include both natural convection, driven by the thermal gradient, and the forced convection, due to the wind speed. The inclusion of the forced convection is important, since the maximum generation of the wind farm, will occur at high wind speeds, when there is an additional convective cooling effect on the $\mathrm{J}$ tube surface. To include both of these convection processes within (17), the heat transfer coefficient on the external surface of the $\mathrm{J}$ tube needs to be modified to consider a combined natural and force convection coefficient. By assuming the wind direction is perpendicular to the natural convection, the combined heat transfer coefficient is considered through

$$
h_{\text {mixed }}=\left(h_{h b}^{2}+h_{f}^{2}\right)^{1 / 2}
$$

Where $h_{h b}$ and $h_{f}$ are the heat transfer coefficient for natural and forced convection. The forced heat transfer coefficient can be defined [19] [15] 


$$
\begin{gathered}
\mathrm{h}_{\mathrm{f}}=\frac{N \mathrm{Nu}_{\mathrm{f}} \kappa_{\mathrm{air}}}{0.5 \mathrm{D}_{\mathrm{o}}} \\
N u_{f}=b R e_{f}^{p} \operatorname{Pr}^{1 / 3} \\
R e_{f}=\frac{V_{a i r} D_{o}}{v}
\end{gathered}
$$

Where $\mathrm{V}_{\text {air }}$ is the air velocity $\left(\mathrm{ms}^{-1}\right)$, which for the following comparison study is assumed to be zero. Hence this removes the forced convection from the example study, leaving $h_{\text {mixed }}$ i.e. Eq. (23) to be defined by the natural convection $\left(\mathrm{h}_{\mathrm{hb}}\right)$ only. The natural heat transfer coefficient $\left(h_{h b}\right)$ is defined by (12), although the temperature difference is now expressed by $T_{j \text { outer }}$ and $T_{\text {surf. }}$.

The solar radiation on the external surface of the $\mathrm{J}$ tube is defined by

$$
q_{\text {solar }}=0.5 A_{\text {Jo }} q_{\text {sun }}
$$

Where $A_{J \text { outer }}$ is the surface area of the J tube and $q_{\text {sun }}$ is the solar radiation from the sun. The additional 0.5 term is used in the equation to account for the fact that only half of the $\mathrm{J}$ tube surface area can be illuminated by the sun at any one time.

\section{E. Thermal Network below Sea level}

The radial thermal network below the sea level is comparable to the $\mathrm{J}$ tube air section, with the only difference being that the convection and radiation terms within the air section are replaced by a solid water domain. The thermal resistance of the water between the cable and the $J$ tube is calculated using the standard thermal resistance equation for an annuls, presented in [5], which is:

$$
\mathrm{T}_{\text {water }}=\frac{\rho_{\text {water }}}{2 \pi} \ln \left[1+\frac{2 \mathrm{t}_{\mathrm{w}}}{D_{\text {cable }}}\right]
$$

Where $t_{w}$ is width of water region (m) between the cable and the $\mathrm{J}$ tube.

\section{F. Thermal Networks for Individual Phases}

Above the $\mathrm{J}$ tube air section, the thermal network only needs to consider one of the separated power cores as the thermal influence of the hang off itself is considered negligible. The thermal network for a single power core is defined by a sub set of the thermal network designed for the $\mathrm{J}$ tube air section, with only $T_{1}$ and $T_{2}$ from [5], because due to the separation of the power cores, the amour layer is no longer present i.e. no need for $T_{3}$. The heat transfer on the external surface of the power core is solved using the same approach as for the external surface of the $J$ tube.

\section{G. Analytical Solution in $2 D$}

Section VI has demonstrated that the $\mathrm{J}$ tube air section is the thermally limiting section and so the continuous rating can be calculated from this section only. By only considering the air section, it is not possible to accurately account for the potential heat transfer to the neighboring cooling sections (Fig.1), which could decrease the temperature of this air section and hence provides a safe estimate of the continuous rating. To calculate the continuous rating for the air section the above energy balance equations are used with an iterative method to balance the applied load with the predicted ambient temperature, as follows. Assuming that the temperature of the conductor is at the thermal limit $\left(\mathrm{T}_{\max }\right)$ at an initial load guess $\left(\mathrm{I}_{\text {rate }}\right)$, the temperature difference on the cable surface can be calculated by

$$
\begin{gathered}
\theta_{c}=\theta_{\max }-\left[I^{2} R_{a c}+0.5 W_{d}\right] T 1+\left[I^{2} R_{a c}\left(1+\lambda_{1}\right)\right. \\
\left.+W_{d}\right] n T_{2}+\left(I^{2} R_{a c} n\left(1+\lambda_{1}+\lambda_{2}\right)\right. \\
\left.+W_{d} n\right) T_{3}
\end{gathered}
$$

Using the cable surface temperature the temperature on the inside surface of the $\mathrm{J}$ tube can be calculated by using the following energy balance

$$
q_{\text {total }}=q_{\text {rad int }}+q_{\text {convint }}
$$

Where $q_{\text {cable }}$ is the sum of the thermal loss within the cable. By substituting the permissible heat flux from the radiation (11) and convection (10) into (30), the remaining term which is unknown is the inside surface temperature of the $\mathrm{J}$ tube. This can be calculated, by re-arranging the equation such that it equals zero and then solving it with a Newton Raphson approach, which is expressed as:

$$
\tilde{\theta}=\theta-\frac{f(\theta)}{f^{\prime}(\theta)}
$$

Where $f(\theta)$ is (30) and $f^{\prime}(\theta)$ is the first order differential with respect to the subject, i.e. $\theta$. The subject of the equation $\theta$ is the current estimation, and the solution of this $\tilde{\theta}$ is used as the next guess value. With the temperature on the inside of $\mathrm{J}$ tube surface known, the temperature on the outside surface can be calculated using (22). The final aspect to consider is the permissible heat flux from the external surface of the $\mathrm{J}$ tube. The energy balance here is solved using (13), with the updated terms presented in (23) through to (26). This equation is then used to predict the ambient air temperature through the Newton Raphson iteration. The predicted ambient temperature ( $\left.T_{\text {surf }}\right)$ is compared against pre-defined air temperature $\left(T_{a m b}\right)$. If the predicted ambient air temperature is not within $2 \%$ of the require temperature the conductor load should be readjusted. If the $\mathrm{T}_{\text {surf }}$ is within the stated $2 \%$ tolerance, then the model is self-consistent and the cable load at this point is the continuous seasonal rating.

\section{H. Analytical Solution in $3 D$}

Section V showed that when the air section length is short there is an increase in the continuous rating due to the longitudinal heat transfer into the neighboring cooler regions. To account for this affect a quasi-3D model for the $\mathrm{J}$ tube is defined with the thermal networks for the water and separate phase sections, as presented above.

The quasi-3D model predicts the conductor's thermal profile within each region separately between $-0.5 \mathrm{~L}_{\mathrm{y}}<\mathrm{z}_{\mathrm{y}}<$ $0.5 \mathrm{~L}_{\mathrm{y}}$, where $\mathrm{L}_{\mathrm{y}}$ is the length of section $\mathrm{y}$, which corresponds to the $\mathrm{J}$ tube air section (a), $\mathrm{J}$ tube water section $(w)$ and separate phase (sep). The position along the length of each section is given by $z_{y}$. The temperature profile within the water and separate section are defined by

$$
\theta_{w}\left(z_{w}\right)=\theta_{2 d_{-} w}+\frac{\left.\frac{\partial \theta_{a}}{\partial z_{w}}\right|_{z=-0.5 L_{a}} e^{m_{w} z}}{m_{w} e^{m_{w} L}}
$$




$$
\theta_{\text {sep }}\left(z_{\text {sep }}\right)=\theta_{2 d_{-} \text {sep }}+\frac{\left.\frac{\partial \theta_{a}}{\partial z_{\text {sep }}}\right|_{z=0.5 L_{a}} e^{m_{\text {sep }} z}}{m_{\text {sep }} e^{m_{\text {sep }} L}}
$$

Where these temperature profiles are bound at the remote end by the respective temperature calculated by the 2D thermal network for either $\mathbf{J}$ tube water $\left(\theta_{2 d_{-} w}\right)$ or separate phase $\left(\theta_{2 d_{-} s e p}\right)$ section. The temperature in these domains is calculated using the predicted 2D rated load from the $\mathrm{J}$ tube air section and then varying the conductor temperature to match the external temperature for that domain i.e. water surface or ambient air temperature.

The temperature profile in the $\mathrm{J}$ tube air section is given by

$$
\theta_{a}\left(z_{a}\right)=\theta_{2 d \_a}-\frac{\frac{\partial \theta_{w}}{\partial z_{a}} \mid e^{-\beta x}}{\beta \mathrm{e}^{0.5 \beta \mathrm{L}_{\mathrm{a}}}}-\frac{\frac{\partial \theta_{s e p}}{\partial z_{a}} \mid e^{\beta z}}{\beta \mathrm{e}^{0.5 \beta \mathrm{L}_{\mathrm{a}}}}
$$

Where the initial central temperature of this region $\left(T_{2 d_{\_} a}\right)$ is given by the conductor thermal limit used to calculate the continuous rating. In the above equations the constants are given by

$$
\begin{gathered}
\beta=\sqrt{\left(\kappa_{c} A_{c}\right)^{-1}\left(T_{1}+T_{2}+T_{3}+T_{\text {air }}+T_{\text {tube }}\right)^{-1}} \\
m_{\text {sep }}=\sqrt{\left(T_{1}+T_{2}\right) /\left(\kappa_{c} A_{c}\right)} \\
m_{w}=\sqrt{\left(T_{1}+T_{2}+T_{3}+T_{\text {water }}\right) /\left(\kappa_{c} A_{c}\right)} \\
T_{\text {air }}=\frac{\theta_{\text {cable }}-\theta_{\text {Jinner }}}{q_{\text {cable }}}
\end{gathered}
$$

Where $\kappa_{\mathrm{c}}\left(\mathrm{Wm}^{-1} \mathrm{~K}^{-1}\right)$ and $\mathrm{A}_{\mathrm{c}}(\mathrm{m})$ are the thermal conductivity and cross sectional area of the conductor and qcable are the total thermal loss within the cable $\left(\mathrm{Wm}^{-1}\right)$.

To complete the three temperature profiles, the temperature and thermal gradient between each section must be equal. These conditions are expressed as

$$
\begin{gathered}
\left.\frac{\partial \theta_{a}}{\partial z}\right|_{z=-0.5 L_{a}}=\left.\frac{\partial \theta_{w}}{\partial z}\right|_{z=0.5 L_{w}} \\
\left.\frac{\partial \theta_{a}}{\partial z}\right|_{z=0.5 L_{a}}=\left.\frac{\partial \theta_{\text {sep }}}{\partial z}\right|_{z=-0.5 L_{w}} \\
\theta_{a}\left(z=0.5 L_{a}\right)=\theta_{\text {sep }}\left(z=-0.5 L_{\text {sep }}\right) \\
\theta_{a}\left(z=-0.5 L_{a}\right)=\theta_{w}\left(z=0.5 L_{w}\right) .
\end{gathered}
$$

The thermal gradients given in (38) and (39) can either be calculated mathematically or through a simpler iterative approach, once the conductor temperature in each 2D model is known. The iterative approach considered by the authors begins by making an initial guess of the thermal gradient which is then iteratively updated until the thermal gradient and the temperature either side of the boundary between the two neighbor domains is the same.

By solving the three thermal profiles and then combing together, the complete conductor thermal profile within a J tube can be obtained.

For short air section lengths, the temperature profile predicted by this method will be less than the thermal limit, due to the longitudinal heat transfer (shown in section V). Under this condition, a more accurate continuous thermal rating can be calculated by adjusting the thermal limit used within the above method, until the complete thermal profile matches the original thermal limit.

\section{COMPARISON OF RESULTS}

A comparison of the conductor temperature profile from the FE model and the 3D analytical model is presented in Fig. 6. In this figure the conductor temperature is shown for various air section lengths at the continuous rating for the $15 \mathrm{~m}$ length. The temperature profile predicted by the FE model and the new analytical method are in general agreement, although the peak temperature of the FE model is lower than that of the analytical model.

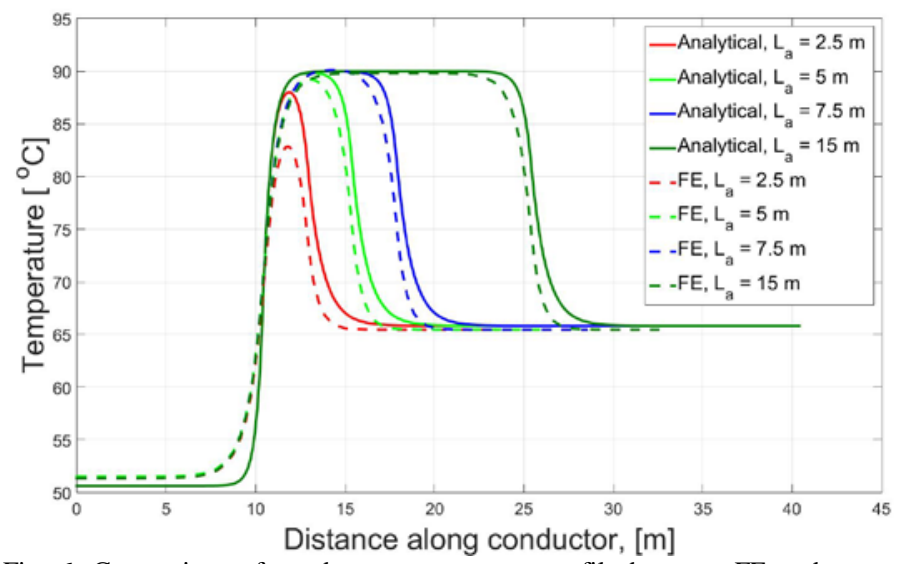

Fig. 6. Comparison of conductor temperature profile between FE and new analytical model. Results are for a continuous rating of $828 \mathrm{~A}$.

This is further shown in Fig. 7 through a comparison of the continuous thermal ratings from each method as a function of the aspect ratio (AR) between the $J$ tube air section length $\left(\mathrm{L}_{\mathrm{a}}\right.$ $[\mathrm{m}]$ ) and cable outer diameter $[\mathrm{m}]$. For $\mathrm{J}$ tube aspect ratios (AR) greater than $34\left(\mathrm{~L}_{\mathrm{a}}>10 \mathrm{~m}\right)$, this figure shows that the proposed analytical model calculates a continuous rating which is $4.7 \%$ less than the FE result. Both the updated 2D analytical method and the new 3D analytical approach produce a better agreement with the FE result, with the ERA method and Hartlein and Black showing 13.3\% and 23.9\% lower rating, respectively. For AR less than $34\left(\mathrm{~L}_{\mathrm{a}}<10 \mathrm{~m}\right)$, the proposed 3D analytical model predicts a further $2.5 \%$ increase in rating from the updated 2D analytical model.

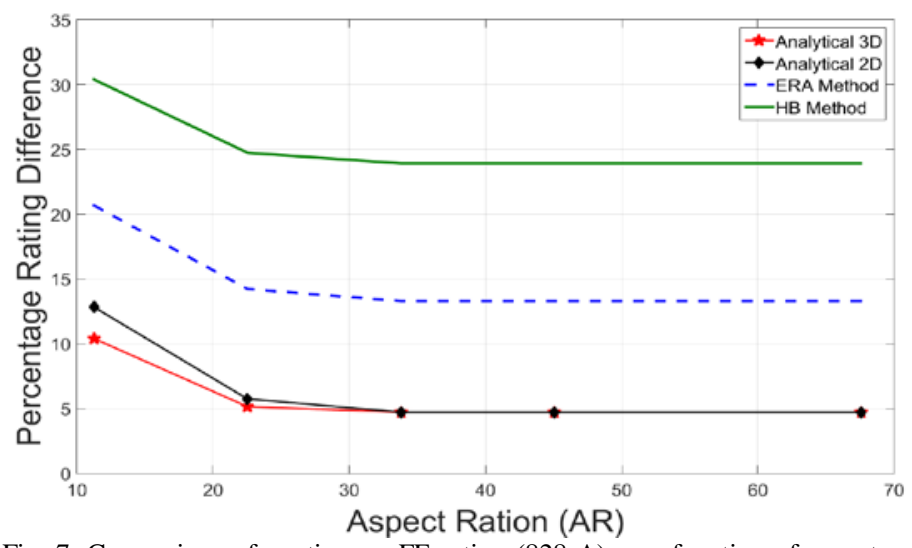

Fig. 7. Comparison of continuous FE rating (828 A) as a function of aspect ratio (AR) for the $1000 \mathrm{~mm}^{2}$ example cable. 


\section{CONCLUSIONS}

At present, no internationally standard method exists for the rating of cables in $\mathrm{J}$ tubes. This paper has developed both 2D and 3D analytical methods to calculate such ratings in the same style as conventional IEC 60287 ratings. This method builds on from the previously published method [14], with an IEC compliant SL cable thermal network, updated heat transfer coefficients from [17] and includes the mixed natural and forced convection on the $\mathrm{J}$ tube surface. To account for longitudinal heat transfer affects, the updated 2D model has been expanded to a quasi-3D model.

The new methods show good agreement with benchmark finite element calculations, with the observed rating differences of around $4 \%$ being less than those found from the use of earlier published approaches. The results obtained demonstrate that a 2D approximation is acceptable for cases where the length of the tube air section is greater than $10 \mathrm{~m}$ (AR < 33). For lengths less than this, the use of the 2D methods becomes conservative and the $3 \mathrm{D}$ calculation is recommended, particularly for wind farm export cables with large conductor sizes. For situations where the $\mathrm{J}$ tube is the most thermally limiting part of the circuit, the methods presented here will facilitate a more accurate sizing of the cable. Accurate cable sizing is an essential part of the cost reductions needed to allow off shore wind to be cost competitive with conventional generation technologies.

\section{APPENDIX}

TABLE A.1. Properties of $132 \mathrm{KV}$ 1000MM² SL TYPE CABLE SYSTEM USED IN EXAMPLE CALCULATIONS

\begin{tabular}{|c|c|c|c|c|}
\hline Geometry & Material & $\begin{array}{c}\text { Thermal } \\
\text { Conductivity } \\
\left(\mathrm{Wm}^{-1} \cdot \mathrm{K}^{-1}\right)\end{array}$ & $\begin{array}{c}\text { Heat } \\
\text { Capacity } \\
\left(\mathrm{MJ} / \mathrm{m}^{3} . \mathrm{K}\right)\end{array}$ & $\begin{array}{l}\text { Radius } \\
\text { (mm) }\end{array}$ \\
\hline Conductor & Copper & 320 & 3.45 & 20 \\
\hline $\begin{array}{l}\text { Conductor } \\
\text { Screen }\end{array}$ & $\begin{array}{c}\text { Semiconducting } \\
\text { XLPE }\end{array}$ & 0.5 & 2.4 & 21.5 \\
\hline Insulation & XLPE & 0.286 & 2.4 & 38.5 \\
\hline $\begin{array}{l}\text { Inulation } \\
\text { Screen }\end{array}$ & $\begin{array}{c}\text { Semiconducting } \\
\text { XLPE }\end{array}$ & 0.5 & 2.4 & 40 \\
\hline Water Tape & Polymer & 0.286 & 2.4 & 41.5 \\
\hline Sheath & Lead & 35.3 & 1.45 & 43.8 \\
\hline Inner Sheath & $\begin{array}{c}\text { Semiconducting } \\
\text { PE }\end{array}$ & 0.5 & 2.4 & 46 \\
\hline $\begin{array}{l}\text { Individual } \\
\text { Bedding }\end{array}$ & $\begin{array}{c}\text { Polypropylene } \\
\text { yarn }\end{array}$ & 0.123 & 1.9 & 101 \\
\hline Armour & Steel & 18 & 3.8 & 106.5 \\
\hline Serving & $\mathrm{PE}$ & 0.2 & 1.7 & 111 \\
\hline $\begin{array}{l}\mathrm{J} \text { tube Inner } \\
\text { Radius }\end{array}$ & Steel & 18 & 3.8 & 237.5 \\
\hline $\begin{array}{l}\mathrm{J} \text { tube Outer } \\
\text { Radius }\end{array}$ & - & - & - & 277.5 \\
\hline- & Water & 0.58 & 4.18 & - \\
\hline- & Air & 0.0242 & $1.27 \times 10^{-6}$ & - \\
\hline
\end{tabular}

TABLE A.2. CABLE SyStem ElECTRICAL PROPERTIES

\begin{tabular}{|c|c|}
\hline Parameter & Value \\
\hline \hline Fill Factor & 0.8 \\
\hline Conductor Resistivity & $1.72 \times 10^{-8} \Omega \mathrm{m}$ \\
\hline Conductor kp & 0.8 \\
\hline Conductor ks & 1 \\
\hline Conductor temp coeff of Resistance & $0.00393 \mathrm{~K}^{-1}$ \\
\hline Sheath Resistivity & $2.14 \times 10^{-7} \Omega \mathrm{m}$ \\
\hline Sheath temp coeff of Resistance & $0.004 \mathrm{~K}^{-1}$ \\
\hline Armour Resistivity & $1.38 \times 10^{-7} \Omega \mathrm{m}$ \\
\hline Armour temp coeff of Resistance & $4.50 \times 10^{-3} \mathrm{~K}^{-1}$ \\
\hline Armour kp & 1 \\
\hline Armour ks & 1 \\
\hline Relative permittivity of Insulation & 2.5 \\
\hline Insulation Tan Delta & 0.001 \\
\hline Voltage of cable & $132 \mathrm{kV}$ \\
\hline Frequency & $50 \mathrm{~Hz}$ \\
\hline
\end{tabular}

\section{REFERENCES}

[1] J. S. González, M. B. Payán and J. R. Santos, "Optimum design of transmissions systems for offshore wind farms including decision making under risk," Renewable Energy, vol. 59, pp. 115 - 127, 2013.

[2] S. Rodrigues, C. Restrepo, E. Kontos, R. T. Pinto and P. Bauer, "Trends of offshore wind projects," Renewable and Sustainable Energy Reviews, vol. 49, pp. 1114-1135, 2015.

[3] P. Chen and T. Thiringer, "Time-Series Based Cable Selection for a Medium Voltage Wind Energy Network," IEEE Transactions on Sustainable Energy, vol. 3, no. 3, p. 465, 2012.

[4] IEC 60287-1-1 ed 2.0, "Electric cables - Calculation of the current rating - Part 1-1: Current rating equations (100 \% load factor) and calculation of losses - General," 2006.

[5] IEC 60287-2-1 ed 2.0, "Electric cables - Calculation of the current rating - Part 2-1: Calculation of Thermal Resistance," 2006.

[6] G. J. Anders, M. Coates and M. Chaaban, "Ampacity Calculations for Cables in Shallow Troughs," IEEE Transactions on Power Delivery, vol. 25, no. 4, pp. 20642072, 2010.

[7] E. Dorison, G. J. Anders and F. Lesur, "Ampacity Calculations for Deeply Installed Cables," IEEE Transactions on Power Delivery, vol. 25, no. 2, pp. 524533, 2010.

[8] A. Sedaghat and F. d. Leon, "Thermal Analysis of Power Cables in Free Air: Evaluation and Improvement of the IEC Standard Ampacity Calculations," IEEE

Transactions on Power Delivery, vol. 29, no. 5, pp. 23062314, 2014.

[9] M. Terracciano, S. Purushothaman, F. de Leon and A. Farahani, "Thermal Analysis of Cables in Unfilled Troughs: Investigation of the IEC Standard and a Methodical Approach for Cable Rating," IEEE Transactions on Power Delivery, vol. 27, no. 3, p. 142.

[10] M. Diaz-Aguilo and F. de Leon, "Introducing Mutual Heating Effects in the Ladder-Type Soil Model for the 
Dynamic Thermal Rating of Underground Cables," IEEE Transactions on Power Delivery, vol. 30, no. 4, pp. 19581964, 2015.

[11] T. Hughes, T. Henstock, J. Pilgrim, J. Dix, T. Gernon and C. Thompson, "Effect of Sediment Properties on the Thermal Performance of Submarine HV Cables," IEEE Transactions on Power Delivery, vol. 30, no. 3, pp. 24432450, 2015.

[12] M. Coates, "Rating cables in J tubes (88-0108)," ERA technology, 1988.

[13] K. Goddard, J. A. Pilgrim, R. Chippendale and P. and Lewin, "Induced Losses in Three-core SL-type High Voltage Cables," IEEE Transactions on Power Delivery, vol. 30, no. 3, pp. 1505-1513, 2015.

[14] R. A. Black and W. Hartlein, "Ampacity of electric power cables in vertical protective rises," IEEE transaction on power apparatus and systems, vol. 102, no. 6, 1983.

[15] G. Anders, Rating Of Electric Power Cables: Ampacity Computations For Transmission, Distribution, And Industrial Applications, McGraw-Hill Professional Publishing , 1997.

[16] M. Keyhani, F. A. Kulacki and R. N. Christensen, "Experimental Investigation of free convection in a vertical rod bundle - A general correlation for nusselt numbers," Journal of Heat Transfer, vol. 107, pp. 611623, 1985.

[17] G. Anders, "Rating of cables on riser poles, in trays, in tunnels and shafts - A Review," IEEE transactions on power delivery, vol. 11, no. 1, pp. 3-11, 1996.

[18] G. Anders and G. Georgallis, "Transient analysis of 3core SL-type submarine cabes with jacket around each core," in Jicable, Paris, 2015.

[19] G. Anders, "Ratings of cables on risers," in Jicable, paris, 1995.

\section{BIOGRAPHIES}

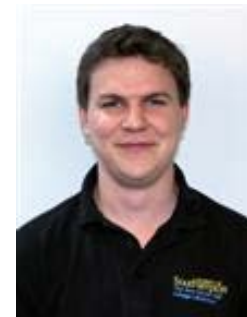

Richard D Chippendale received the Master's degree in Physics from University of Southampton in 2009. He pursued his doctoral degree at the same university, investigating the thermal and chemical degradation to composite materials due to a lightning strike, for which he was awarded a PhD in 2013. He is currently employed as a Research Fellow, working on a variety of projects related to high voltage cable systems. He is a member of IEEE DEIS and an associate member of the IOP.

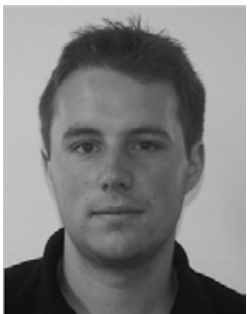

James A. Pilgrim (M'09) received the Bachelor's degree in electrical engineering from the School of Electronics and Computer Science at the University of Southampton in 2007. He joined the staff of the University of Southampton in 2007 as a Research Assistant, gaining his $\mathrm{PhD}$ in 2011. He joined the academic staff of the University in 2012. His research interests include all aspects of high voltage cables and associated insulation systems. $\mathrm{He}$ is currently the Treasurer of the UKRI Chapter of the IEEE DEIS and a member of the DEIS Technical Committee on Smart Grid.
He is actively involved in the development of current rating methodologies, acting as the UK member of IEC TC 20 WG19 (Current Rating and Short Circuit Limits of Cables) and Cigre Working Group B1.35 "Guide to rating calculations”.

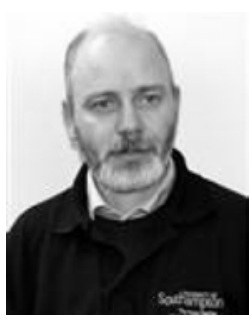

Kevin F. Goddard received the B.Sc. degree in electrical engineering from the University of Southampton, Southampton, U.K., in 1982.

After two years as a graduate trainee at NEI Parsons, he returned to Southampton to research stray flux behavior in the core frames of large machines. He then worked on the design and modeling of various electromagnetic devices for various research projects.

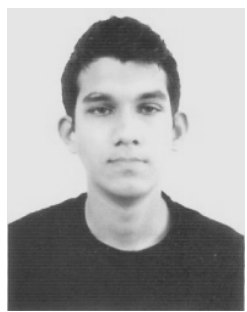

Priank Cangy was born in Maputo, Mozambique on the 5th of April, 1993. He is currently studying at the University of Southampton for an MEng in Electrical Engineering, having recently completed an internship at the Tony Davies High Voltage Laboratory. 